Language and Cognition 12 (2020), 310-342. doi:10.1017/langcog.2019.47

(C) UK Cognitive Linguistics Association, 2020. This is an Open Access article, distributed under the terms of the Creative Commons Attribution licence http://creativecommons.org/ licenses/by/4.0/, which permits unrestricted re-use, distribution, and reproduction in any medium, provided the original work is properly cited.

\title{
Conceptual metaphors in poetry interpretation: a psycholinguistic approach*
}

\author{
CARINA RASSE \\ ALEXANDER ONYSKO \\ Department of English and American Studies, Universität Klagenfurt, Austria
}

A N D

FRANCESCA M. M. CITRON

Department of Psychology, Lancaster University, UK

(Received 2 August 2019 - Revised 17 November 2019 - Accepted 22 November 2019)

ABSTRACT

Psycholinguistic research has shown that conceptual metaphors influence how people produce and understand language (e.g., Gibbs, 1994, 2017a; Kövecses, 2015; Jacobs \& Kinder, 2017). So far, investigations have mostly paid attention to non-poetic metaphor comprehension. This focus stems from the original discovery of Conceptual Metaphor Theory that much of everyday, non-poetic language is metaphorical. The present study aims to expand this focus and explores whether people access conceptual metaphors during poetry interpretation. To answer this question, we conducted a psycholinguistic experiment in which 38 participants, all native speakers of English, completed two tasks. In each

[*] We would like to thank the poets for making their work available for the study and for taking part in the research project. The participation of the people in the study is also thankfully acknowledged. We are grateful to two anonymous reviewers for their insightful and constructive comments on an earlier version of the paper. Finally, we would like to thank Hermann Cesnik for consultation in statistical matters. This work was funded by the travel and research grant from the University of Klagenfurt, awarded to Carina Rasse. Carina Rasse and Francesca Citron conceived and designed the study, Carina prepared the online surveys, recruited and tested participants, analyzed the data, and wrote up most of the manuscript. Francesca contributed to data analysis and writing up, with particular focus on method and results. Alexander Onysko contributed to the design of the study, to the data analysis and to the writing up. Address for correspondence: Carina Rasse, Department of English and American Studies, Alpen-Adria-Universität Klagenfurt, Austria, Universitätsstraße 65-67, 9020 Klagenfurt, Austria. e-mail: carina.rasse@aau.at 
task, participants read excerpts of poetry containing conceptual metaphors before selecting or rating items that indicated their implicit and explicit awareness of the conceptual metaphors. The results of both tasks show that participants retrieve conceptual metaphors when reading poetry. This provides empirical evidence in favor of the idea that crucial aspects of poetic thought and language arise from conceptual metaphor.

KEYWORDS: conceptual metaphors, figurative language, metaphors, poetry, literary metaphors

\section{Introduction}

Metaphor is a fundamental part of our imagination and language. Via metaphor one "speak[s] of something as though it were another" (Richards, 1936, p. 116). In poetry, as in other literary forms of art, the author can establish a similarity relation between two entities, as in John Keats's (1819) famous saying "Beauty is truth, truth beauty - that is all" or in Shakespeare's (1597) "Juliet is the sun". When scholars theorize about the nature of metaphor in literature, they often focus on the artistic nature of figurative language. At the same time, research in psycholinguistics and related fields has shown that literary metaphors are rooted in the same unconscious thought patterns and bodily experiences as conventional metaphors (Gibbs, 1990, 1999, 2017b). Thus, they neither violate standard communicative norms nor require a special talent to be produced or understood, as proposed earlier (cf., e.g., Grice, 1975; Searle, 1980).

The currently most dominant approach within the large, diverse multidisciplinary area of metaphor research is Conceptual Metaphor Theory (CMT), which proposes that metaphor is omnipresent also in non-literary language and that it shapes the ways people think, act, and communicate (Lakoff \& Johnson, 1980). To take just one example, in Western cultures our concept of time is partly structured by the knowledge that we have about money. This is reflected in common English expressions, such as "Time is money", "She spends her time unwisely", and "The diversion should buy him some time". According to CMT, people think and talk about time by mapping the knowledge that they have about the concrete source domain "money" onto the abstract target domain of "time". The underlying conceptual metaphor is T I ME IS MONEY. Some other common conceptual metaphors are LOVE IS A JOURNEY (e.g., "We've hit a crossroads in this relationship"), PEOPLE ARE PLANTS ("She's in her flower of youth"), and G O O D I S U P ("That's a high-quality paper"). The main claim of this cognitive-linguistic approach is that we all automatically and unconsciously use such conceptual cross-domain mappings to get a better understanding of abstract concepts that we encounter in our everyday lives. 
Apart from studying conceptual metaphors in language use, recent investigations in the cognitive sciences have gathered empirical evidence for the existence of conceptual metaphors in non-verbal realms, such as images, sound, and body language (e.g., Gibbs, 2006, 2017a; Bergen, 2012; Forceville, 2012; Kövecses, 2015; also see Casasanto \& Gijssels, 2015, or Hampe, 2017, for critical discussions). For instance, people were shown to use upward beat gestures, motivated by the G O O D IS U P conceptual metaphor, when talking about the weather getting better, and employ downward gestures when speaking about buying a car for a cheap price (LESS IS DOWN). Furthermore, extensive research has stressed the importance of embodied simulation processes in people's engagements with figurative language (e.g., Soriano \& Valenzuela, 2009; Colston, 2019). For instance, Boroditsky and Ramscar (2002) explored how people's very recent embodied actions affected their understanding of time metaphors. People waiting in line at a cafe were given the statement "Next Wednesday's meeting has been moved forward two days" and then asked "What day is the meeting that has been rescheduled?" People who have been advancing further in the queue were more likely to say that the meeting was moved to Friday instead of Monday, thus associating their forward motion in space with their perception of time.

The notion that conceptual knowledge and embodied experiences are also central to people's understanding of literary metaphors has been explored thoroughly in Turner's The Literary Mind (1996) and Lakoff and Turner's More than Cool Reasons (1989). One of the authors' main arguments is that metaphorical creativity in poetry is the result of common devices that poets use in manipulating conceptual metaphors that they share with everyday people. This also explains why readers, as suggested by Lakoff and Turner, draw on pre-existing conceptual mappings rather than creating novel metaphorical mappings to understand novel poetic language (1989, pp. xi-xii). This view has been taken up and further elaborated in numerous other works (e.g., Kövecses, 1994; Steen \& Gibbs, 2004; Camp, 2008; Semino \& Steen, 2008; Yang, 2015). Most of these studies are based on close readings of literary narratives and/or on systematic identifications of conceptual metaphors in (poetic) discourse (e.g., Deignan, 2005; Pragglejaz Group, 2007; Steen, 2007; Steen et al., 2010) rather than on empirical investigations into how readers process poetic metaphors.

Our current study aims to address this lacuna and explores empirically whether readers access conceptual metaphors during poetry interpretation or not. A psycholinguistic experiment consisting of two tasks was designed to shed some light on this issue. In Task 1, participants rated lexical items that were related or unrelated to the underlying conceptual metaphors present in stanzas of poetic texts. Task 2 involved the selection of conceptual 
metaphors from a set after reading longer excerpts from the same poems. Before introducing the design of the study and discussing the results, the next section will provide an overview of previous research on metaphor processing in poetry.

\section{Previous research on metaphor processing in poetry}

Research on metaphor processing in literary narratives so far has been characterized by little collaboration between the cognitive sciences and the humanities when it comes to the study of how literary narratives are processed by readers. Furthermore, empirical approaches to the study of literature reception, such as Cognitive Poetics or Neurocognitive Poetics, have given very little attention to the role of conceptual metaphors in the production and processing of poetic language. At the same time, only a handful of studies in psycholinguistics have focused on the role of conceptual metaphors in poetry interpretation.

\subsection{COGNITIVE POETICS}

An empirical approach to the study of literature reception that combines methods from the cognitive sciences and the humanities is known as Cognitive Poetics. It has its roots in the 1970s and is defined as "a theoretical methodology that explains how poetic language and literary form are shaped and constrained by human cognitive processes" (Tsur, 2017, p. vii). Cognitive Poetics expanded in the late 1990s, driven by increasing interest from literary scholars in conceptual metaphor, figure and ground, and schema- and world-theories (e.g., Freeman, 2000; Stockwell, 2006; Giovanelli, 2013; also see Freeman, 2007, or Csabi, 2018, for further discussions). Regarding the study of metaphor, a cognitive poetic approach explores "how the general mapping skills that constitute the cognitive ability to create and interpret metaphor can provide a more coherent theory than the intuitive and ad hoc approaches of traditional criticism" (Freeman, 2000, p. 253). For instance, Popova (2002) explored how metaphorical mappings of smell in Patrick Süskind's novel Perfume contribute to the emergence of the text's theme. Furthermore, Bertuol (2001) studied the writings of the poet Margaret Cavendish to show how the conceptual metaphor UN IVERSE IS MATHEM A T I C S shaped how people viewed reality back in the seventeenth century. In general, it can be said that Cognitive Poetics broadens the classical theories in literary studies by taking into account how poetic language and form is constrained by human cognitive processes. Yet, scholars in that field mainly draw on already existing studies in cognitive science instead of conducting empirical research themselves. 


\subsection{NEUROCOGNITIVE POETICS}

A recently developed approach that builds on theories of Cognitive Poetics but also studies the neuronal and cognitive-affective bases of literary reading is called Neurocognitive Poetics. Its focus lies on empirical investigations into how the brain processes poetic language and creates meaning and pleasure out of the various bits and pieces that construct a poem, such as sounds and images, figures of thought (e.g., polysemy, irony, meiosis, oxymoron) or figures of speech (e.g., euphemism, simile, metaphor) (Jacobs, 2015). One extensive study was conducted by Jacobs and Kinder (2017) on metaphor processing that aimed, among other issues, at identifying the strongest predictors of 'metaphor goodness', i.e., how apt or pleasing the metaphors were. ${ }^{1}$ Some key findings of the study indicate that sentences are more likely to be judged as metaphorically meaningful if the vehicle is concrete, and that ambiguous metaphors produce higher aesthetic liking (e.g., Byron's "a broken heart is a shattered mirror, reflecting life in pieces"; Shakespeare's "the sun is the eye of heaven”). However, as the examples show, the corpus was limited to metaphors of the type 'A is B', that are relatively rare in discourse. Furthermore, the study did not explicitly test for the role of conceptual metaphor in the processing of poetic metaphors.

Another study that focused on metaphor appreciation was conducted by Littlemore, Sobrino, Houghton, Shi, and Winter (2018). It differs from Jacobs and Kinder's (2017) investigation as it paid significantly more attention to conceptual metaphors. Yet, it explored people's reactions to non-literary, computer-generated metaphors (e.g., 'love is a beautiful painting'; 'business is relaxing music'). One of their findings is still highly relevant to the present project: the researchers found that people were more likely to detect meaning in conventional and moderately innovative metaphors than in highly innovative ones. This, as the authors explain, suggests that "people have an awareness of or preference for conceptual metaphor, even if it is at a subconscious level: If there is a conceptual metaphor that can be identified then the metaphor is preferred” (2018, p. 117). More generally, this finding implies that, when readers encounter conventional or moderately innovative metaphors, the underlying conceptual metaphors are accessed. But does the same apply to the processing of poetic metaphors?

[1] Jacobs and Kinder reanalyzed the corpus of 204 literary metaphors created by Katz et al. (1988) using a combination of quantitative narrative analysis, latent semantic analysis, and machine learning in order to identify relevant features of the metaphors that influenced the ratings. 


\subsection{PSYCHOLINGUISTIC PERSPECTIVES ON THE STUDY OF METAPHORS IN POETRY}

While the question of whether the processing of metaphors in poetry requires readers to access conceptual metaphors has so far received relatively little attention in the field of (Neuro)cognitive Poetics, some studies in psycholinguistics have focused on the role of conceptual metaphors in poetry interpretation. A series of studies by Gibbs and Nascimento (1996) showed how pre-existing conceptual metaphors constrain people's interpretation of metaphors in love poetry. In their first study, participants were asked to write about the concept of love and about their personal love experiences. The responses have shown that people use conventional expressions that reflect enduring metaphorical conceptualizations of love such as LOVE IS UNITY, LOVE IS A VALUABLE RESOURCE, or LOVE IS A JOURNEY. In their second study, participants were asked to read segments of poetry and to choose those conceptual metaphors from a list that they think best reflected the meaning of the presented poem. The researchers found that participants performed very well in this task as the selected conceptual metaphors reflected the theme of the poetic fragments that they had just read. The third experiment showed very similar results when a different group of people was asked to select conventional expressions from a list of five that best reflected the concept of love described in the poem. In their final study, Gibbs and Nascimento used think-aloud protocols to assess whether the ways people talk about the metaphorical meaning of selected poems reflect their everyday metaphorical understanding of love. The results showed that this was indeed the case. For example, when participants interpreted the meaning of Pablo Neruda's poem Ode and Burgeoning, they referred to entailments of the L OVE IS A J O URNEY conceptual metaphor, such as the path (e.g., participants reported a special road that the characters in the poem could travel on together), the goals (e.g., the future of their love lay ahead of them), and the impediments to travel (e.g., they managed to get over the rough places). Overall, Gibbs and Nascimento concluded that, across all poems and participants, $78 \%$ of the responses in the think-aloud protocols made references to conceptual metaphors that were underlying the theme or topic of the presented poems.

The relevance of conceptual metaphor in the understanding of poetry is consistent with the findings of two other investigations. In one study, Gibbs and Boers (2005) analyzed people's written interpretations of Robert Frost's poem 'The Road Not Taken' and found that participants made indirect references to the LIFE IS A JOURNEY conceptual metaphor by reporting its typical entailments (e.g., the poet is the traveler, difficulties are obstacles). Additionally, Gibbs and Boers pointed out that numerous participants described how they imagined themselves walking through the woods as part

of their in-the-moment comprehension of the poem. These results suggest that 
people make sense of Frost's poem and draw relevant metaphorical inferences through embodied simulation processes.

In another series of empirical studies, Gibbs and Okonski (2018) analyzed participants' written interpretations of Adrienne Rich's poem 'Diving into the Wreck', which describes the diving experience of a scuba diver. Participants were divided into four groups and were asked to read the poem following one of four different instructions. In the first condition, the guidelines suggested the literal interpretation of Rich's poem. In the second condition, participants were given the idea that the poem describes a failed relationship. The third prompt encouraged participants to consider multiple meanings of the poem, and no explicit instructions about how the poem should be read were given in the fourth setting. Gibbs and Okonski's main finding was that, regardless of how they were instructed, almost all participants articulated the metaphorical/allegorical theme of the poem by making references to source domains that refer to embodied experiences (e.g., a metaphorical journey into a damaged psyche).

The discussion of previous studies on metaphors in poetry has shown that this topic has been of interest to scholars from different disciplines. A variety of methods were employed to explore what metaphors may reveal about the text structure, how metaphors influence readers' understanding of poetic narratives, what the use of figurative language tells readers or researchers about the authors or the times in which the poem was written, and which cognitive and aesthetic processes metaphors can evoke. Yet, except for a handful of studies, the role of conceptual metaphors in the processing of poetic metaphors has received relatively little attention. This tendency stems, most likely, from the original proposal of conceptual metaphor theory that much of everyday, non-poetic language is metaphorical. Additionally, one of the main methodological challenges in both poetic and non-poetic contexts is to get verbal proof of whether (or not) conceptual metaphors are activated. The present study attempts to shed more light on these issues. In the following section, the methodological design of the study is explained.

\section{Method}

The different components of the experiment are outlined below, covering participants, materials, procedure, and data analysis. The study was approved by the Faculty of Science and Technology Research Ethics Committee at Lancaster University and follows the ethical guidelines of the American Psychological Association.

\subsection{PART I C I P A N T S}

Thirty-eight students at Lancaster University participated in the study (29 females and 9 males between 18 and 63 years of age, mean 22.74, SD 8.02). All participants were native speakers of English and received $£ 5$ for their 


\section{CONCEPTUAL METAPHORS IN POETRY}

participation. At the beginning of the experiment, participants filled out a form to gather information on their gender, age, and occupation. In addition, they indicated their knowledge in their first language and in any other languages they speak. Participants were informed that all personal details remain confidential and that they can withdraw from the study at any time. A signed informed consent was obtained from every participant. Since one participant only completed the first task, Task 2 had a total of 37 participants ( 28 females and 9 males, 18-63 years, mean 22.76, SD 8.13).

\subsection{MATERIA LS}

\subsubsection{Poems and stanzas}

The excerpts of poetry used in the two tasks were gathered from the following English-speaking poets: Mark Olival-Bartley ('Metaphor'), Jason D. Peterson ('How We Got Here'), Rae Armantrout ('The Difficulty'), Frank Beck ('The Copper Husk Allegory'), Shirley Lim ('Night Vision'), James Arthur ('Wind'), and Robert Pinsky ('The Hearts'). A total of 14 two-line stanzas of six of the poems listed above were used for Task 1, and 8 longer stanzas (mean length: 7 lines) from all seven poems were chosen for Task 2 .

The selection of stimuli for the two tasks was based on four criteria: (1) all poets are contemporary writers; this is important as the postulation of conceptual metaphors was partly based on the poets' own interpretations of their works; ${ }^{2}$ (2) non-canonical poems were chosen so that participants would not be familiar with these materials and therefore not be potentially influenced by pre-existing interpretations; (3) the selected poetic fragments depicted different metaphorical themes which could all be understood in their immediate context; this means that, for the purposes of this study, it was sufficient to use excerpts of poetry instead of the entire poem; (4) the materials chosen involve metaphorical themes and topics that are common (e.g., life, death, love, possession, personification) and include a mapping that could be traced back to an established or slightly modified conceptual metaphor present in the Master Metaphor List (Lakoff, Espenson, \& Schwartz, 1991). A full list of the poetic excerpts used in the study and their underlying conceptual metaphors can be found in 'Appendix A'.

\subsubsection{Task 1: relatedness ratings}

In the first part of the study, a relatedness rating task was used to explore whether participants rate words that refer to a conceptual metaphor expressed

[2] As part of a larger project, the first author conducted online interviews in which she asked poets to reflect upon their use of metaphors in their works. Based on the poets' interpretations of selected passages, conceptual metaphors were postulated that best described the metaphoric meanings in the passages. 
RASSE ET AL

T A B LE 1. Descriptive and inferential statistics of the related and unrelated words used in Task 1

\begin{tabular}{|c|c|c|c|c|c|}
\hline \multirow[b]{2}{*}{ Variables } & \multicolumn{2}{|c|}{ Related words } & \multicolumn{2}{|c|}{ Unrelated words } & \multirow[b]{2}{*}{ T-test } \\
\hline & Mean & SD & Mean & SD & \\
\hline Length in letters & 7.11 & 2.14 & 7.07 & 2.58 & $\mathrm{t}(110)=0.08, \mathrm{~ns}$ \\
\hline Frequency per million words & 9.61 & 2.18 & 9.45 & 1.34 & $\mathrm{t}(91.49)=0.46, \mathrm{~ns}$ \\
\hline Semantic distance (LSA) & 0.13 & 0.07 & 0.13 & 0.06 & $\mathrm{t}(110)=0.72, \mathrm{~ns}$ \\
\hline
\end{tabular}

NOTES: Degrees of freedom were corrected in case of significantly unequal variance. Frequency per million words was taken from the Hyperspace Analogue to Language (HAL; Lund \& Burgess, 1996) and extracted from the English Lexicon Project (ELP; Balota et al., 2007). Semantic distance is based on Latent Semantic Analysis (LSA; Landauer and Dumais, 1997).

in the two-line stanza as more related to the stanza than words that are not connected to the metaphor. For instance, the line The farmhouse is still / Against a voiceless hill from Beck's 'The Copper Husk Allegory' contains the conceptual metaphor A H ILL IS A PERSON, which involves the mapping of human attributes from the source domain (PERSON) to the inanimate target domain (HILL). According to the hypothesis that people perform crossdomain mappings when they encounter poetic metaphors, we assumed that participants would rate words that refer to the source or the target domain of the conceptual metaphor (in this case human, child, mother, father) as more highly related than words that are unrelated to the metaphor (i.e., door, cupboard, desk, chair).

A set of 4 related and 4 unrelated words were created for each of the 14 twoline stanzas. All 8 words for a particular stanza belonged to the same word class; they were either nouns or verbs. Overall, the 56 related and 56 unrelated words were statistically equal in length, frequency, and semantic distance from the content words contained in their respective two-line stanzas (see Table 1 for descriptive and inferential statistics). Word frequency per million was extracted from the English Lexicon Project (Balota et al., 2007) and is based on the Hyperspace Analogue to Language (HAL) frequency norms (Lund \& Burgess, 1996). Semantic distance was extracted from the Latent Semantic Analysis (LSA) database (Landauer \& Dumais, 1997). LSA is a contextual theory of meaning in that it represents the meaning of a word by its relationships to other words in a semantic space. To construct this semantic space, it analyses word co-occurrences in a large number of written documents and represents the meaning of a word or sentence by a vector of 300 numbers (see Kintsch \& Bowles, 2002). ${ }^{3}$

[3] An introduction to the theory and method and further references are given in Landauer, Foltz, and Laham (1998). 


\subsubsection{Task 2: conceptual metaphor selection}

In Task 2, participants read 8 poetic stanzas, all of similar length (Mean = 7 lines), and were asked to select up to 3 conceptual metaphors from a list of 6 metaphors. The instructions to Task 2 provided the participants with an explanation of what a conceptual metaphor is, and an example of a poem and its underlying conceptual metaphor were given (see 'Appendix B'). Then, the participants were asked to select those metaphors that they thought best describe the meaning of each stanza.

In contrast to the previous task, we used longer stretches of the poems to provide the participants with more text, i.e., potential confounds for their metaphor selections (see 'Appendix D'). The lists of metaphors contained at least one conceptual metaphor and not more than three that occurred in the stanzas, and reflected the meanings of the selected stanzas. These were considered as target metaphors. Additionally, each of the lists included at least one conceptual metaphor that was postulated based on the responses of the authors (see footnote 2). Frank Beck, for instance, said in his response to the question about his choice of metaphors that he was thinking of the cold winter season. Beck said that 'being still' or 'sleeping', in the farmhouse is still, may be interpreted as people in the farmhouse that are suffering or dead (Beck, 2017). For this reason, the conceptual metaphor DEA T H IS S LEEP was added to the list. In addition, each list comprised at least one conceptual metaphor that was lexically or semantically similar to one underlying conceptual metaphor, but was actually unrelated, such as FI E L D S A RE P E O P LE for the same stanza. The remaining conceptual metaphors in the list were unrelated to the poem but are common ways of thinking about abstract concepts, such as NEGATIVE IS DOWN Or LIFE IS A JOURNEY. The rationale for creating such sets of conceptual metaphors for each of the poetic excerpts was to hone in on the question of whether participants choose the proper metaphors from the sets.

\subsection{PRO CEDURE}

Participants were recruited through the SONA System, a web-based resource for participant recruitment used at Lancaster University. The study was also advertised at the Departments of Psychology and of Linguistics \& English Language at Lancaster as well as on social media. In the advert, a quick description of the study was provided, and it was explicitly mentioned that no knowledge in literary interpretation was required. If candidates decided to participate in the study, they were given a URL to complete the online survey, which was designed using Qualtrics. There was no time limit to complete the task.

In Task 1 (relatedness rating), participants were asked to read 14 two-line stanzas taken from different contemporary poems and to rate the relatedness of 8 words displayed on a list next to the stanza. The related and unrelated items 
on this list were presented in the same random order (see list of words for each stanza in 'Appendix A'). The degree of relatedness was indicated on a Likert scale from 1 (not at all related) to 4 (very much related). The two-line stanzas and their corresponding sets of words were presented in different randomized orders across participants.

After completing the relatedness ratings, the participants continued with Task 2. To introduce the task, a definition of metaphor was provided, and an example of a conceptual metaphor in poetry illustrated how conceptual metaphors work (see 'Appendix B'). After that, the participants were presented with 8 excerpts of poetry (one after the other), each followed by a list of 6 conceptual metaphors which were given in the same random order. For each of the excerpts, the participants were asked to select up to 3 metaphors that "best describe the theme or topic of the poem". The participants were asked to decide intuitively and not to think about each poem for too long.

\subsection{DATA ANALYSIS}

The data was analyzed using SPSS. Significance thresholds are set to $p<.05$ in both tasks unless otherwise specified in the 'Results and discussion' section. To calculate effect sizes for independent-samples and paired-samples $t$-tests, Cohen's $d$ has been used: $d=0.20$ is considered a small effect size, $d=0.50$ medium, $d=0.80$ or above large. For ANOVAs, partial eta squared $\left(\eta^{2}\right)$ has been calculated: $\eta^{2}=$ 0.01 is considered a small effect size, $\eta^{2}=0.06$ medium, $\eta^{2}>0.14$ large.

\subsubsection{Task 1}

For each related and unrelated word, mean relatedness ratings across all participants were calculated. An independent-samples $t$-test was conducted to compare all single related and unrelated words, across the two-line stanzas. In addition, to further explore differences within each stanza, the individual ratings from each participant for each stanza and each related and unrelated word were analyzed through a series of repeated-measures ANOVAs, one per stanza, with factors Relatedness (related, unrelated) and Individual word (word 1, 2, 3, 4). We are aware of the fact that this latter factor is rather unconventional because the words from 1 to 4 in the related and unrelated sets have nothing specific in common. Nevertheless, considering individual words as a factor in the ANOVA allows us to look at the individual contributions that the words have to the overall relatedness scores within the related and unrelated sets. In these analyses, only the main effects of Relatedness and interactions between Relatedness and Individual words were tested. If a significant interaction between the two factors was observed at $p \leq .001$, then further post-hoc comparisons between the individual words were conducted to identify any 'unexpected cases', i.e., any instances in which words receive particularly high or low ratings. 


\subsubsection{Task 2}

Out of the 6 conceptual metaphors that participants could choose from, the number of target metaphors that relate to the theme of the poems varied between 2 and 4. The remaining ones functioned as unrelated distractors. Because of the variability in number between target metaphors and distractors across poems, the following scoring procedure was devised: for each participant and poem, the number of correct choices was divided by the total number of target metaphors for that poem; similarly, the number of incorrect answers was divided by the total number of distractor metaphors for that poem. The two proportional scores of correct and incorrect choices were averaged across all participants, separately for each poem. A paired-samples $t$-test was conducted to compare the mean proportions of correctly selected target metaphors to the mean proportions of incorrect selections for the 8 poems. In addition, differences for each single poem were analyzed by comparing the raw proportions of target and distractor metaphors from all participants in 8 separate paired-samples $t$-tests for each of the 8 poems.

\section{Results and discussion}

The raw data collected in both tasks will be publicly available at <https:// osf.io/zqm82/> after the first author has completed her doctoral thesis.

\subsection{TASK I : RELATEDNESS RATINGS}

On a scale from 1 (not at all related) to 4 (very much related), ${ }^{4}$ metaphor-related words were rated as significantly more strongly related to their respective stanza $($ Mean $=2.45, S D=0.64, \min -\max =1.24-3.87)$ compared to unrelated words $($ Mean $=1.46, S D=0.38$, min-max $=1.03-2.63 ; t(89.60)=9.90, p<.001$, Cohen's $d=1.86$ ), and the effect size is large. This result may be taken as an indication that associative relatedness is influenced by underlying conceptual metaphors. When taking a close look at the ratings per poetic stanza, this finding is confirmed in that a significant main effect of relatedness is found in each stanza, and all effect sizes are large (all $\eta s^{2}>0.14$; Table 2).

While the statistical results can be interpreted as providing support for the hypothesis that readers access conceptual metaphors when reading the different poetic stanzas, it is worth taking a closer look at the individual un/related words to determine potential effects of their individual ratings. A first quantitative gauge of that is given in Table 2, which reports the ANOVA results of

[4] Mean relatedness ratings across the 4 related and the 4 unrelated words were also calculated and a $t$-test conducted to compare the 14 means between the two conditions. The results were very similar to the ones reported in the main text, i.e., mean relatedness ratings were significantly higher for related words (Mean $=2.45, S D=0.49)$ than unrelated words, and the effect size is large $($ Mean $=1.46, S D=0.29 ; t(26)=6.48, p<.001$, Cohen's $d=2.46)$. 
T A B LE 2. Descriptive statistics of relatedness ratings for related and unrelated words for each stanza, and main effects of relatedness and interactions of relatedness by individual word

\begin{tabular}{lllll}
\hline & \multicolumn{2}{l}{ Related words } & Unrelated words & \\
\cline { 2 - 3 } Stanza & Mean (SD) & Mean (SD) & Main effect of relatedness (ANOVA) & $\begin{array}{c}\text { Interaction Relatedness by } \\
\text { Individual word (ANOVA) }\end{array}$ \\
\cline { 2 - 3 } 1) Beck 1 & $1.41(0.39)$ & $1.18(0.31)$ & $\mathrm{F}(1,37)=12.86, \mathrm{p}=.001,>2=.26$ & $\mathrm{~F}(2.14,79.31)=11.87, \mathrm{p}<.001,>2=.24$ \\
2) Beck 2 & $2.41(0.56)$ & $1.81(5.10)$ & $\mathrm{F}(1,37)=21.05, \mathrm{p}<.001,>2=.36$ & $\mathrm{~F}(3,111)=54.69, \mathrm{p}<.001,>2=.60$ \\
3) Beck 3 & $2.53(0.55)$ & $1.46(0.34)$ & $\mathrm{F}(1,37)=185.03, \mathrm{p}<.001,>2=.83$ & $\mathrm{~F}(3,111)=17.04, \mathrm{p}<.001,>2=.32$ \\
4) Peterson 1 & $2.92(0.70)$ & $1.59(0.48)$ & $\mathrm{F}(1,37)=102.07, \mathrm{p}<.001,>2=.73$ & $\mathrm{~F}(2.35,86.98)=4.23, \mathrm{p}<.05,>2=.10$ \\
5) Peterson 2 & $2.05(0.67)$ & $1.58(0.52)$ & $\mathrm{F}(1,37)=13.47, \mathrm{p}=.001,>2=.27$ & $\mathrm{~F}(2.43,89.74)=5.08, \mathrm{p}<.01,>2=.12$ \\
6) Lim 1 & $2.68(0.57)$ & $1.28(0.27)$ & $\mathrm{F}(1,37)=181.38, \mathrm{p}<.001,>2=.83$ & $\mathrm{~F}(2.37,87.54)=19.17, \mathrm{p}<.001,>2=.34$ \\
7) Lim 2 & $2.15(0.55)$ & $1.14(0.26)$ & $\mathrm{F}(1,37)=108.04, \mathrm{p}<.001,>2=.75$ & $\mathrm{~F}(2.24,82.81)=2.90, n s$ \\
8) Lim 3 & $2.64(0.59)$ & $1.17(0.25)$ & $\mathrm{F}(1,37)=223.81, \mathrm{p}<.001,>2=.86$ & $\mathrm{~F}(3,111)=32.88, \mathrm{p}<.001,>2=.47$ \\
9) Pinsky 1 & $3.16(0.67)$ & $1.59(0.54)$ & $\mathrm{F}(1,37)=114.48, \mathrm{p}<.001,>2=.76$ & $\mathrm{~F}(3,111)=8.38, \mathrm{p}<.001,>2=.19$ \\
10) Pinsky 2 & $2.62(0.75)$ & $1.84(0.57)$ & $\mathrm{F}(1,37)=32.19, \mathrm{p}<.001,>2=.47$ & $\mathrm{~F}(3,111)=.14, n s$ \\
11) Pinsky 3 & $2.25(0.68)$ & $1.35(0.41)$ & $\mathrm{F}(1,37)=70.00, \mathrm{p}<.001,>2=.65$ & $\mathrm{~F}(3,111)=1.78, n s$ \\
12) Lim 4 & $1.86(0.65)$ & $1.30(0.37)$ & $\mathrm{F}(1,37)=32.44, \mathrm{p}<.001,>2=.47$ & $\mathrm{~F}(3,111)=12.09, \mathrm{p}<.001,>2=.25$ \\
13) Armantrout & $3.23(0.50)$ & $2.08(0.60)$ & $\mathrm{F}(1,37)=123.69, \mathrm{p}<.001,>2=.77$ & $\mathrm{~F}(3,111)=21.07, \mathrm{p}<.001,>2=.36$ \\
14) Arthur & $2.44(0.79)$ & $1.14(0.26)$ & $\mathrm{F}(1,37)=114.61, \mathrm{p}<.001,>2=.76$ & $\mathrm{~F}(3,111)=6.54, \mathrm{p}<.001,>2=.15$ \\
\hline
\end{tabular}

NOTE: Only significant interactions at $p \leq .001$ were further explored post-hoc. 
the interaction between relatedness and the individual words. The results show that significant interactions between relatedness and individual words at $p \leq$ .001 , all with large effect sizes $\left(\eta s^{2}>0.14\right)$, were found in 9 out of the 14 stanzas. A post-hoc analysis of these instances serves as the basis for drawing further conclusions on differences between individual words. To single out the individual words, two repeated-measures ANOVAs were conducted for each stanza for the related and unrelated word sets separately (factor individual word). Because of the inevitable differences between single words and, therefore, the likelihood of finding significant differences between all words, a significance threshold of $p \leq .001$ was set for the main effects of individual word too. Only for word sets that would reach this threshold were further contrasts explored. The contrasts were defined after visual inspection of the descriptive statistics: for sets in which one word would differ from all others, Helmert contrasts were defined; for sets in which two words would differ from two other words, simple contrasts were defined comparing word pairs. As these contrasts were exploratory (we had no specific a priori directional hypothesis), and because 16 possible comparisons were possible within each set, the standard significance threshold of $p<.05$ was divided by 16 and the new threshold set to $p<.003$. Only contrasts reaching this threshold were deemed significant and therefore interpreted and discussed. Table 3 shows only the significant contrasts conducted for each stanza when the main effects of an individual word were significant. Descriptive statistics (means and standard deviation) of all metaphor-related and metaphor-unrelated target items discussed in this section are summarized in 'Appendix C'.

To exemplify the results summarized in Table 3, let us take a closer look at poem 14. In 'Arthur' (At times the wind embraces you so lightly / in ways you don't even register as touch), we postulated the conceptual metaphor W IND IS A PERSON based on the personification of the wind in the stanza. If readers unconsciously draw on this association, the lexical items 'partner', 'friend', 'parent', and 'care', all of which relate to the source domain of the metaphor (PERSON), should receive higher ratings than the unrelated words 'bike', 'plane', 'boat', and 'transportation'. Figure 1 shows that this was indeed the case.

Among related words, the target item 'care' got the highest mean rating (2.79), followed by 'friend' (2.53) and 'partner' (2.42). The related item 'parent' got the lowest mean rating (2.03) and was significantly lower than all other 3 words in the set. We propose that the participants' ratings might have been shaped by people's understanding of the concept 'parent', which might not prototypically be associated to the level of intimacy expressed in the poetic imagery in "Arthur'. The line At times the wind embraces you so lightly / in ways you don't even register as touch prompted readers to think of a person that shares a more intimate relationship (e.g., a lover or friend). As a hyperonym, 'parent' is also a more formal and possibly less affectively laden term than, for example, 'mum' and 'dad'. This 
T A B LE 3. List of significant contrasts between individual words conducted for each stanza with specification of their direction. All significant contrasts have large effect sizes ( all $\eta s^{2}>0.14$ )

\begin{tabular}{|c|c|c|c|c|}
\hline \multirow[b]{3}{*}{ Poems } & \multicolumn{4}{|c|}{ Contrasts } \\
\hline & \multicolumn{2}{|c|}{ Related words } & \multicolumn{2}{|c|}{ Unrelated words } \\
\hline & Contrast run & F-test & Contrast run & F-test \\
\hline 1) Beck 1 & no significant main effect & $\begin{array}{l}- \\
F(137)=19162 n<001\end{array}$ & door $>$ other words & $\begin{array}{l}\mathrm{F}(1,37)=13.91, \mathrm{p}<.003 \\
\quad \mathrm{\eta} 2=.27\end{array}$ \\
\hline 2) Beck 2 & to rest $>$ other words & $\begin{array}{l}\mathrm{F}(1,37)=191.62 \mathrm{p}<.001 \\
\quad \eta 2=.84\end{array}$ & to wonder $>$ to rely $\&$ to dig & $\begin{array}{l}\text { Fs }(1,37)>12.72, \text { ps }<.003, \\
\eta s 2>.26 \\
F s(1,37)>28.44, \text { ps }<.001,\end{array}$ \\
\hline 3) Beck 3 & journey $>$ other words & $\begin{array}{l}\mathrm{F}(1,37)=63.56 \mathrm{p}<.001, \mathrm{\eta} 2 \\
\quad=.63\end{array}$ & $\begin{array}{l}\text { to stay }>\text { to rely } \& \text { to } \mathrm{dig} \\
\text { revolution }>\text { celebration } \& \\
\quad \text { assistance }\end{array}$ & $\begin{array}{l}\eta \mathrm{s} 2>.44 \\
\mathrm{Fs}(1,37)>15.79, \mathrm{ps}<.001 \\
\eta \mathrm{s} 2>.30\end{array}$ \\
\hline 6) $\operatorname{Lim} 1$ & $\begin{array}{l}\text { to live }>\text { to breathe } \& \text { to } \\
\text { grow }\end{array}$ & $\begin{array}{l}\mathrm{Fs}(1,37)>12.04, \mathrm{ps}<.003 \\
\quad \eta 2>.25\end{array}$ & to cry $>$ other words & $\begin{array}{l}\mathrm{F}(1,37)=24.86, \mathrm{p}<.001 \\
\quad \mathrm{\eta} 2=.40\end{array}$ \\
\hline & $\begin{array}{l}\text { to exist }>\text { to breath } \& \text { to } \\
\text { grow }\end{array}$ & $\begin{array}{l}\mathrm{Fs}(1,37)>40.43, \mathrm{ps}<.001 \\
\quad \eta 2>.52 \\
\mathrm{~F}(1,37)=141.98 \mathrm{p}<.001\end{array}$ & & \\
\hline 8) $\operatorname{Lim} 3$ & doctor $<$ other words & $\eta 2=.79$ & no significant main effect & - \\
\hline 9) Pinsky 1 & no significant main effect & - & reflection $>$ other words & $\begin{array}{l}\mathrm{F}(1,37)=27.85, \mathrm{p}<.001 \\
\mathrm{\eta} 2=.43\end{array}$ \\
\hline 12) $\operatorname{Lim} 4$ & suicide $<$ death & $\begin{array}{l}\mathrm{F}(1,37)=26.20, \mathrm{p}<.001, \mathrm{n} 2 \\
\quad=.42\end{array}$ & disgust $>$ other words & $\begin{array}{l}\mathrm{F}(1,37)=12.21, \mathrm{p}=.001 \\
\quad \eta 2=.25\end{array}$ \\
\hline & torture $<$ death & $\begin{array}{l}\mathrm{F}(1,37)=27.12, \mathrm{p}<.001, \mathrm{n} 2 \\
\quad=.42\end{array}$ & food $<$ other words & $\begin{array}{l}\mathrm{F}(1,37)=14.89, \mathrm{p}<.001 \\
\quad \eta 2=.29\end{array}$ \\
\hline 13) Armantrout & break-up $<$ other words & $\begin{array}{l}\mathrm{F}(1,37)=105.41, \mathrm{p}<.001 \\
\mathrm{\eta} 2=.74 \\
\mathrm{~F}(1,37)=40.87, \mathrm{p}<.001, \mathrm{\eta} 2\end{array}$ & journey $>$ other words & $\begin{array}{l}\mathrm{F}(1,37)=15.82, \mathrm{p}<.001 \\
\quad \mathrm{\eta} 2=.30\end{array}$ \\
\hline 14) Arthur & parent $<$ other words & $=.53$ & no significant main effect & - \\
\hline
\end{tabular}

NO TE: Only significant main effects of Individual word at $p \leq .001$ were investigated further through contrasts. For contrasts, the significance threshold was set at $p<.003$. Refer to the main text for the rationale behind these thresholds. 


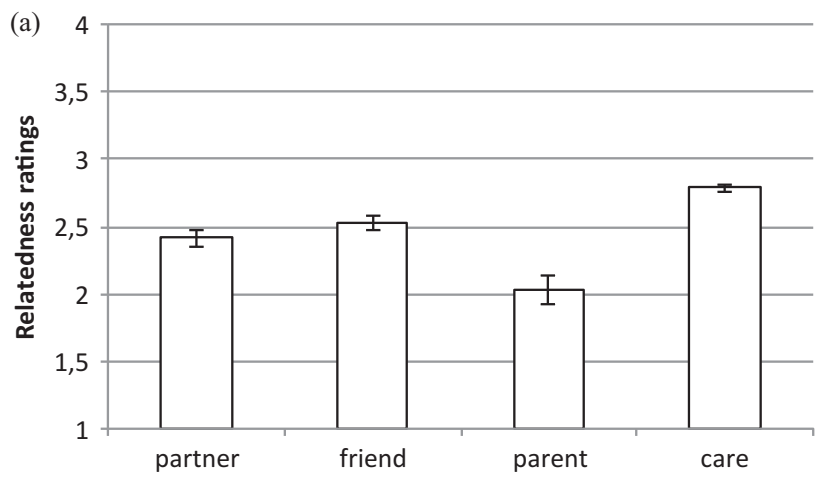

Arthur: Related words

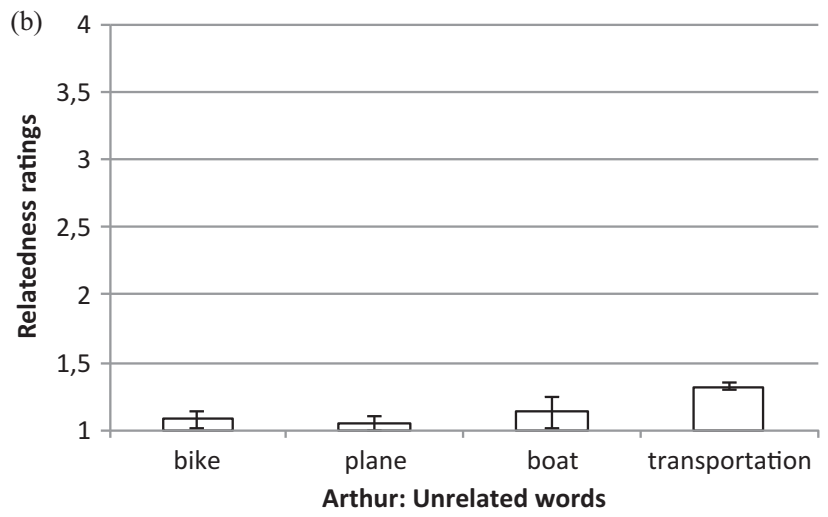

Fig. 1. Mean ratings of metaphor-related (a) and metaphor-unrelated (b) words for the poem 'Arthur'. Relatedness ratings range from 1 (not at all related) to 4 (very much related). Error bars represent \pm 1 SEM.

finding suggests that participants' relatedness ratings were also influenced by different semantic associations between the stanzas and the lexical items. All four metaphor-unrelated words were given low ratings (all lower than 1.4) with no significant differences between individual words.

Similar to the previous example, semantic specificity has most likely influenced the ratings of words related to another poem in which significant contrasts between individual words were found (see Table 3). In 'Lim 3' (Years later than in a crib / floating among the white moon faces that beam and grasp), the target word 'doctor' received significantly lower ratings than the three related words 'mother', 'family', and 'people' (see 'Appendix C'). Our assumption is that 'doctor' is too specific for the scene described in the poem.

Literal relations between certain words in the list and the excerpts of poetry have apparently encouraged participants to rate certain target items higher 
than the others within a set. In 'Beck 2' (One farmer is sitting in the darkened barn / The motor's singing him to sleep), for instance, the related item 'rest', which refers to the literal meaning of the stanza, got the highest mean rating and was significantly higher than the other 3 items 'decay', 'die', and 'vanish', which refer to the metaphorical meaning instead. This could also be an explanation for why the item 'stay', which is semantically similar to 'rest', but was considered as unrelated to the underlying conceptual metaphor DEA TH IS SLEEP, still got significantly higher ratings than the items 'rely' and 'dig' in the set of metaphor-unrelated words. To 'wonder' got the highest mean rating within the set of metaphor-unrelated words as it matches the literal scene depicted in the poem: a farmer is sitting and reflecting on things.

A similar pattern was found in the set of unrelated words in 'Pinsky 1'. In that case, 'reflection' was rated significantly higher than the other 3 words ('calculation', 'distance', and 'deliberation'). Our assumption is that 'wanting' and 'grieving' in The legendary muscle that wants and grieves / The organ of attachment, the pump of thrills describe mental states which are closer to the conceptualization of reflection as a mental state, and consequently prompted readers to see 'reflection' as being more closely related to the stanza.

In some other cases, the literal meaning of the stanza seemed to be the main reason why certain lexical items received particularly low ratings. For instance, in 'Lim 4' (Years later, I awaken to see / Dust falling in the dark, in the house), the related items 'suicide' and 'torture' were rated significantly lower than 'death'. Our explanation is that the notions of 'suicide' and 'torture' conflict with the lyrical ' $\mathrm{I}$ ' in the poem being alive and observing a scene of decay, which is more in synchrony with the more general notion of death rather than the specific, more aggressive and arousing concepts of torture and suicide. In the case of 'Beck 1', the concept of house in The farmhouse is still / Against a voiceless hill has, most likely, encouraged people to see the metaphor-unrelated but semantically close item 'door' as being more related to the stanza compared to the other 3 unrelated words 'cupboard', 'chair', and 'desk'.

Some of the results give rise to the observation that, within the sets of metaphor-related words, participants' relatedness ratings were influenced by whether certain metaphor-related words were linked to either the domain or the entailments of certain conceptual metaphors. In 'Beck 3', 'journey' connects directly to the source domain as lexically prompted by 'way' in Only one farmer / has sought the way of pain and got significantly higher ratings than all other 3 related words 'acceptance', 'confrontation', and 'encounter', which are entailments of the conceptual metaphor LIFE IS A DIFFICULT J OURNEY. The same is true for 'Lim 1', where 'exist' and 'live', both relating directly to the conceptual metaphor ALIVE IS AWAKE, were each rated significantly more related to the poem than 'breathe' and 'grow', which can be considered as entailments of the conceptual metaphor. Also in 'Armantrout', the 3 items 
'ending', 'conclusion', and 'closure', which relate directly to the conceptual metaphor EN D I N G S A RE R O L L I N G C R E D I T S, received higher ratings than 'break-up', which relates to an entailment of the conceptual metaphor.

Overall, our results have shown that participants perceived connections between the metaphor-related terms and the conceptual metaphors expressed in the poem. In fact, the metaphor-related words were rated as significantly more strongly connected to their respective stanzas compared to the unrelated words. The occurrence of some outliers (target items which were rated significantly higher or lower than the other words within one set) indicates that the processing of metaphors is complex and is shaped by different interacting factors. One of these factors was semantic specificity which, depending on the context, led participants to give specific words particularly high or low ratings. Additionally, we could observe that participants' relatedness ratings varied depending on whether the target words referred to the literal meaning of the poetic stanza or to the metaphorical. When there was a close literal match, people rated these items as more related than the non-literal ones within related and unrelated sets of words. Furthermore, participants' relatedness ratings varied depending on whether the target items related directly to the conceptual metaphors or to their entailments. The latter finding is particularly interesting as it suggests that there is usually not one single, fixed conceptual metaphor that is accessed during the processing of poetic metaphors. Instead, readers may recruit aspects of the underlying conceptual metaphor without necessarily activating a fully composed structure that includes the cross-domain mapping and all of its entailments, or even two or more conceptual metaphors and/or their entailments at the same time. This assumption will be further discussed in Section 4.2.

\subsection{TASK 2: CONCEPTUAL METAPHOR SELECTION TASK}

The target metaphors were chosen significantly more often $($ Mean $=0.56, S D$ $=0.08$ ) than the distractor metaphors, and the effect size is large (Mean $=0.12$, $S D=0.08 ; t(7)=10.19, p<.001$, Cohen's $d=5.50)$. This was the case for each single poem, too, as can be seen in Table 4 . The first 2 poems have medium effect sizes (Cohen's $d \geq 0.45$ ), while the remaining 6 poems have large effect sizes (Cohen's $d \geq 0.80$ ).

Compared to Task 1, which confirmed the participants' implicit activation of conceptual metaphors when reading poetry, Task 2 shows that people's explicit reflection on conceptual metaphors guides them towards appropriate choices. Table 5 summarizes how often in each of the poems the individual conceptual metaphors were selected.

Table 5 shows that, in general, various metaphorical conceptualizations are at play when people read poetry. In 'How We Got Here', for instance, the conceptual metaphor REPRESSING IS EATING was selected most 
TABLE 4 Mean proportions of correct and incorrect metaphors for each poem and their $t$-test results

\begin{tabular}{|c|c|c|c|c|c|}
\hline \multirow[b]{2}{*}{ Poem } & \multicolumn{2}{|c|}{$\begin{array}{l}\text { Proportion } \\
\text { target } \\
\text { metaphors }\end{array}$} & \multicolumn{2}{|c|}{$\begin{array}{l}\text { Proportion } \\
\text { distractor } \\
\text { metaphors }\end{array}$} & \multirow[b]{2}{*}{ T-test } \\
\hline & Mean & SD & Mean & SD & \\
\hline \multicolumn{6}{|l|}{ The Copper Husk } \\
\hline Allegory & 0.46 & 0.34 & 0.24 & 0.22 & $\mathrm{t}(36)=2.72, \mathrm{p}=.01$, Cohen's $\mathrm{d}=0.45$ \\
\hline How we got here & 0.52 & 0.24 & 0.19 & 0.27 & $\mathrm{t}(36)=4.67, \mathrm{p}<.001$, Cohen's $\mathrm{d}=0.77$ \\
\hline Night Vision (1) & 0.61 & 0.25 & 0.10 & 0.15 & $\mathrm{t}(36)=9.22, \mathrm{p}<.001$, Cohen's $\mathrm{d}=1.52$ \\
\hline Metaphor & 0.68 & 0.27 & 0.17 & 0.18 & $\mathrm{t}(36)=8.12, \mathrm{p}<.001$, Cohen's $\mathrm{d}=1.33$ \\
\hline The Hearts & 0.51 & 0.20 & 0.04 & 0.10 & $\mathrm{t}(36)=14.46, \mathrm{p}<.001$, Cohen's $\mathrm{d}=2.38$ \\
\hline Night Vision (2) & 0.52 & 0.23 & 0.03 & 0.09 & $\mathrm{t}(36)=12.35, \mathrm{p}<.001$, Cohen's $\mathrm{d}=2.03$ \\
\hline The Difficulty & 0.67 & 0.16 & 0.05 & 0.12 & $\mathrm{t}(36)=19.39, \mathrm{p}<.001$, Cohen's $\mathrm{d}=3.19$ \\
\hline Wind & 0.51 & 0.26 & 0.10 & 0.19 & $\mathrm{t}(36)=6.50, \mathrm{p}<.001$, Cohen's $\mathrm{d}=1.07$ \\
\hline
\end{tabular}

frequently. The same conceptual metaphor was also used indirectly in Task 1 , as the four mapping-related items 'to subdue', 'to suppress', 'to control, and 'to keep back' are based on this conceptual metaphor. In this sense, Task 2 supports the findings of Task 1 in that conceptual metaphors are evoked as the participants read the poetic stanzas. Frequently, this does not only hold for one of the metaphors, but it tends to extend to all related metaphors in a stanza, e.g., POSSESSION IS EATING and TRYING TO GET IS EATING were selected 15 times each in 'How We Got Here'.

In general, participants always selected more than one conceptual metaphor from the pre-given list. These findings suggest that people can recruit more than one conceptual metaphor when they encounter abstract topics. In the case of 'Night Vision 2', for instance, participants saw the context-specific, creative conceptual metaphor DEATH IS FALLING DUST as a fitting conceptualization of the themes that the poem depicts. In addition, participants also selected the much broader, more common conceptual metaphor ALIVE IS AWAKE from the list. This implies that people thought about the poem in different metaphorical ways. This was the case for all poems that were used in the study.

\section{General discussion and conclusion}

The present study used a novel empirical approach to explore whether readers access conceptual metaphors during poetry interpretation. Task 1 consisted of relatedness-ratings that studied people's implicit retrieval of conceptual metaphors in contemporary poetry. The results showed that words which relate to a conceptual metaphor that underlies the meaning of the presented poem were rated as significantly more related to the poetic stanza compared to 
T A B LE 5. Overview of results in Task 2 (target conceptual metaphors in bold)

\begin{tabular}{|c|c|c|}
\hline poems & pre-defined CMs (correct ones in bold) & $\begin{array}{l}\text { how often } \\
\text { each CM } \\
\text { was selected }\end{array}$ \\
\hline \multicolumn{3}{|l|}{ Copper Husk } \\
\hline \multirow{6}{*}{ Allegory } & DEATH IS SLEEP & 16 \\
\hline & A HILL IS A PERSON & 18 \\
\hline & LIFE IS A JOURNEY & 7 \\
\hline & NEGATIVE IS DOWN & 4 \\
\hline & FALLING DUST IS DEATH & 14 \\
\hline & FIELDS ARE PEOPLE & 11 \\
\hline \multirow[t]{6}{*}{ How We Got Here } & REPRESSING IS EATING & 28 \\
\hline & POSSESSION IS EATING & 15 \\
\hline & TRYING TO GET IS EATING & 15 \\
\hline & THE HEART IS THE CENTER OF EMOTION & 8 \\
\hline & DREAMING IS EATING & 5 \\
\hline & AFFECTION IS WARMTH & 1 \\
\hline \multirow[t]{6}{*}{ Night Vision (1) } & ALIVE IS AWAKE & 23 \\
\hline & AFFECTION IS CONTAINMENT & 15 \\
\hline & WHITE MOON FACES ARE PEOPLE & 31 \\
\hline & WATER IS BLOOD & 0 \\
\hline & IMPORTANT IS HEAVY & 1 \\
\hline & DEAMING IS FLOATING & 10 \\
\hline \multirow[t]{6}{*}{ Metaphor } & RHYTHM IS MOVING WATER & 18 \\
\hline & A POEM IS A BOAT & 33 \\
\hline & UNLIMITEDNESS IS WATER & 9 \\
\hline & PERSISTENCE IS CLINGING ENTITIES & 4 \\
\hline & LOVE IS A JOURNEY & 5 \\
\hline & A BOAT IS A PERSON & 5 \\
\hline \multirow[t]{6}{*}{ The Hearts } & THE HEART IS THE CENTER OF EMOTION & 34 \\
\hline & PERSISTENCE IS CLINGING ENTITIES & 8 \\
\hline & THE HEART IS A CONTAINER & 16 \\
\hline & POSSESSION IS EATING & 0 \\
\hline & DREAMS ARE COLONIES & 4 \\
\hline & CLOSENESS IS INTIMACY & 0 \\
\hline \multirow[t]{6}{*}{ Night Vision (2) } & DEATH IS FALLING DUST & 30 \\
\hline & ALIVE IS AWAKE & 19 \\
\hline & TO FLECK IS TO DISTRACT & 9 \\
\hline & TASTE IS ENJOYMENT & 1 \\
\hline & AFFECTION IS CONTAINMENT & 0 \\
\hline & DESIRE IS HUNGER & 2 \\
\hline \multirow[t]{6}{*}{ The Difficulty } & BEING UNIMPORTANT IS BEING SMALL & 5 \\
\hline & ENDINGS ARE ROLLING CREDITS & 32 \\
\hline & LIFE IS A MOVIE & 37 \\
\hline & DIFFICULTIES ARE ANIMALS & 1 \\
\hline & EMOTIONS ARE ENTITIES WITHIN A PERSON & 4 \\
\hline & DEATH IS FALLING DUST & 0 \\
\hline \multirow[t]{7}{*}{ Wind } & THE WIND IS A PERSON & 29 \\
\hline & TO BEHAVE LIKE THE WIND IS TO DISAVOW & \\
\hline & RESPONSIBILITIES & 11 \\
\hline & TO BE LIKE THE WIND IS TO BE MISCHIEVOUS & 17 \\
\hline & THE WIND IS A BUILDING & 0 \\
\hline & ALIVE IS AWAKE & 3 \\
\hline & PROGRESS IS FORWARD MOVEMENT & 8 \\
\hline
\end{tabular}


metaphor-unrelated words. This result supports our assumption that associative relatedness is influenced by conceptual metaphors. Importantly, our results could not be explained by more general factors such as semantic distance between target words and their stanza, as this was equal between related and unrelated words. When taking a close look at the ratings per poetic stanza, this finding was confirmed in that a significant main effect of relatedness was found in each stanza. In addition, significant interactions between relatedness and individual words were found in 9 out of the 14 stanzas. This finding showed that participants' ratings varied within the set of related and unrelated lexical items. We analyzed the individual words in detail through post-hoc tests to explore what factors have possibly influenced the ratings. This step was crucial as previous studies have often assumed that metaphor is a final, static product that has only one specific kind of linguistic meaning (see Gibbs, 2017c, for a critical discussion).

So far, little attention has been paid to the fact that different, interacting factors may influence the production and processing of metaphors. Besides the association between source and target domains, the present study considers alternative associative pathways that have possibly influenced the results. Our interpretations of the collected data suggest that different semantic processes seem to be at play. Participants' relatedness-ratings varied depending on whether the lexical items related directly to the underlying conceptual metaphors or to their entailments. In some cases, the expressions in the poetic stanzas seemed to have prompted readers to associate certain target items that represent superordinate or basic level terms linked to the underlying conceptual metaphor. Moreover, relations between certain words in the list and the literal description of the poetic scene sometimes influenced participants' ratings. Since we did not find a single overall pattern of choices (e.g., participants did not always rate words that depict the literal meaning of the poem higher than words that depict the metaphorical meaning), we concluded that the context of the poem together with the conceptual metaphors play a significant role in people's relatedness ratings.

This assumption was supported by the results from Task 2, which showed that participants selected the expected conceptual metaphors significantly more often than the distractors. Furthermore, our discussion has shown that, in all cases, more than one conceptual metaphor was seen as being representative of the meaning of the presented poetic stanza. Our assumption, again, is that the selection of conceptual metaphors was strongly influenced by the context of the poem. For instance, some poems evoked very specific images (e.g., a child lying in a crib or the wind flipping an umbrella inside out), others depicted more abstract topics (e.g., starving memories, clinging troubles). In some poems, the narrative voice was positive, optimistic, in others gloomy or melancholic. Depending on these factors, participants' selections of the 'fitting' conceptual metaphors ranged from conceptualizations at a schematic level to conceptualizations at a more specific, conceptually rich level. 


\section{CONCEPTUAL METAPHORS IN POETRY}

One possible limitation of our study is that the findings from the relatednessrating and the conceptual metaphor selection tasks reflect processing that takes place after the poems/stanzas have been read rather than during reading. Hence, readers may have seen the connections between lexical items or conceptual mappings and the presented stanzas only after reading comprehension, and because of being prompted by the tasks. However, previous research has shown that comprehension and interpretation processes unfold over a long time-window, well beyond word meaning retrieval (e. g., Sitnikova, Holcomb, \& Kuperberg, 2008), and especially so in the case of literary metaphors (Bambini, Canal, Resta, \& Grimaldi, 2019). Although our tasks do not tap into cognitive processes $a t$ the point of poetic text exposure, they nonetheless reflect residual comprehension and interpretation processes generated during text exposure. In fact, consistent association to conceptual-metaphor-related words and to underlying conceptual metaphors in each stanza would not be possible if readers had not accessed such metaphors during exposure. By explicitly asking participants to evaluate the relevance of different words and to choose between different metaphors, conceptual metaphor access and usage is enhanced. Still, a proper analysis requires a combination of different methods. In the case of our study, think-aloud protocols may be used in future investigations to get verbal justifications for why certain conceptual metaphors or lexical items were selected or rated particularly highly by the participants. Furthermore, one could prime readers to interpret specific metaphors under different conditions (e.g., no information on the author vs. adding biographical details about the poet's life). This method would enable one to define, more precisely, how context shapes the interpretation of poetic metaphors.

Despite these limitations, the findings of our study are of value to readers and writers of poetry alike. Knowing how individual words, which form the basis of metaphorical conceptualizations, shape the interpretation and creation processes of poetic metaphors may help poets to better understand the readers' reactions to specific metaphors. Readers, on the other hand, can gain insights into how metaphors in poetry work on an implicit level and trigger certain associations and emotions. A further step would be to ascertain whether our methods may also be applied to the study of metaphors in other types of discourse and how far these findings are also representative of metaphor processing in non-verbal forms of communication.

\section{REFERENCES}

Balota, D. A., Yap, M. J., Cortese, M. J., Hutchison, K. A., Kessler, B., Loftis, B., Neely, J. H., Nelson, D. L., Simpson, G. B. \& Treiman, R. (2007). The English Lexicon Project. Behavior Research Methods 39, 445-459.

Bambini, V., Canal, P., Resta, D. \& Grimaldi, M. (2019). Time course and neurophysiological underpinnings of metaphor in literary context. Discourse Processes 56, 77-97. 


\section{RASSE ET AL}

Beck, F. (2017). interviewed by C. Rasse. What do metaphors mean to you?

Bergen, B. K. (2012) Louder than words: the new science of how the mind makes meaning. New York: Basic Books.

Bertuol, R. (2001). The square circle of Margaret Cavendish: the 17-century conceptualization of mind by means of mathematics. Language and Literature 10, 21-39.

Boroditsky, L. \& Ramscar, M. (2002). The roles of body and mind in abstract thought. Psychological Science 13, 185-189.

Camp, E. (2008). Showing, telling, and seeing: metaphor and poetic language. Baltic International Yearbook of Cognition, Logic and Communication 3, 1-24.

Casasanto, D. \& Gijssels, T. (2015). What makes a metaphor an embodied metaphor? Linguistics Vanguard 1(1), 327-337.

Colston, H. L. (2019). How language makes meaning: embodiment and conjoined antonymy. Cambridge: Cambridge University Press.

Csabi, S. (ed.) (2018). Expressive minds and artistic creations: studies in cognitive poetics. Oxford: Oxford University Press.

Deignan, A. (2005). Metaphor and corpus linguistics. Amsterdam \& Philadelphia: John Benjamins.

Forceville, C. (2012). Creativity in pictorial and multimodal advertising metaphor. In R. Jones (ed.), Discourse and creativity (pp. 113-132). Harlow: Pearson.

Freeman, M. (2000). Poetry and the scope of metaphor: toward a theory of cognitive poetics. In A. Barcelona (ed.), Metaphor and metonymy at the crossroads: a cognitive perspective (pp. 253-281). Berlin: Mouton de Gruyter.

Freeman, M. (2007). Cognitive linguistic approaches to literary studies: state of the art in cognitive poetics. In D. Geeraerts \& H. Cuyckens (eds), The Oxford handbook of cognitive linguistics (pp. 1175-1202.). Oxford and New York: Oxford University Press.

Gibbs, R. (1990). The process of understanding literary metaphor. Fournal of Literary Semantics 19, 65-94.

Gibbs, R. (1994). The poetics of mind: figurative thought, language, and understanding. New York: Cambridge University Press.

Gibbs, R. (1999). Intentions in the experience of meaning. New York: Cambridge University Press.

Gibbs, R. (2006). Embodiment and cognitive science. New York: Cambridge University Press.

Gibbs, R. (2017a). Metaphor wars: conceptual metaphor in human life. New York: Cambridge University Press.

Gibbs, R. (2017b). Embodied dynamics in literary experience. In M. Burke \& E. Troscianko (eds), Dialogues between literature and cognition (pp. 219-239). New York: Oxford University Press.

Gibbs, R. W. (2017c). Metaphor, language, and dynamical systems. In V. Koller, E. Semino \& Z. Demjen (eds), Routledge handbook of metaphor and language (pp. 56-69). London: Routledge.

Gibbs, R. \& Boers, E. (2005). Metaphoric processing of allegorical poetry. In Z. Maalej (ed.), Metaphor and culture (pp. 44-61). Tunis: University of Manouba Press.

Gibbs, R. \& Nascimento, S. (1996). How we talk when we talk about love: metaphorical concepts and understanding love poetry. In R. Kreuz \& M. MacNealy (eds), Empirical approaches to literature and aesthetics (pp. 221-240). Norwood, NJ: Ablex.

Gibbs, R. \& Okonski, L. (2018). Cognitive poetics of allegorical experience. In S. Csabi (ed.), Expressive minds and artistic creations: studies in cognitive poetics (pp. 33-55). New York: Oxford University Press.

Giovanelli, M. (2013). Text world theory and Keats’ poetry. New York \& London: Bloomsbury Publishing.

Grice, H. (1975). Logic and conversion. In P. Cole \& J. Morgan (eds), Syntax and semantics (pp. 113-127). New York: Academic Press.

Hampe, B. (ed.) (2017). Metaphor: embodied cognition and discourse. Cambridge: Cambridge University Press.

Jacobs, A. (2015). Neurocognitive poetics: methods and models for investigating the neuronal and cognitive-affective bases of literature reception. Frontiers in Human Neuroscience 9, e00186. 


\section{CONCEPTUAL METAPHORS IN POETRY}

Jacobs, A. \& Kinder, A. (2017). The brain is the prisoner of thought: a machine learning assisted quantitative narrative analysis of literary metaphors for use in neurocognitive poetics. Metaphor and Symbol 32(3), 139-160.

Katz, A., Paivio, A., Marschark, M. \& Clark, J. (1988). Norms for 204 literary and 260 non- literary metaphors on psychological dimensions. Metaphor and Symbolic Activity 3(4), 191-214.

Kintsch, W. \& Bowles, A. R. (2002). Metaphor comprehension: What makes a metaphor difficult to understand? Metaphor and Symbol 17, 249-262.

Kövecses, Z. (1994). Tocqueville's passionate 'beast': a linguistic analysis of the concept of American democracy. Metaphor and Symbolic Activity 9, 113-133.

Kövecses, Z. (2015). Where metaphors come from: reconsidering context in metaphor. New York: Oxford University Press.

Lakoff, G., Espenson, J. \& Schwarz, A. (1991). Master metaphor list (second draft copy). Berkeley, CA: University of California at Berkeley. Online <http://araw.mede.uic.edu/ $\sim$ alansz/metaphor/METAPHORLIST.pdf $>$.

Lakoff, G. \& Johnson, M. (1980). Metaphors we live by. Chicago, IL: University of Chicago Press.

Lakoff, G. \& Turner. M. (1989). More than cool reason: a field guide to poetic metaphor. Chicago: University of Chicago Press.

Landauer, T. K. \& Dumais, S. T. (1997). A solution to Plato's problem: the latent semantic analysis theory of acquisition, induction, and representation of knowledge. Psychological Review 104(2), 211-240.

Landauer, T. K., Foltz, P. W. \& Laham, D. (1998). An introduction to latent semantic analysis. Discourse Processes 25(2/3), 259-284.

Littlemore, J., Sobrino, P., Houghton, D., Shi, J. \& Winter, B. (2018). What makes a good metaphor? A cross-cultural study of computer-generated metaphor appreciation. Metaphor and Symbol 33(2), 101-122,

Lund, K. \& Burgess, C. (1996). Producing high-dimensional semantic spaces from lexical co-occurrence. Behavior Research Methods, Instruments, छ Computers 28, 203-208.

Popova, Y. (2002). 'The fool sees with his nose': metaphoric mappings in the sense of smell in Patrick Suskind's Perfume. Language and Literature 12, 135-151.

Pragglejaz Group (2007). A practical and flexible method for identifying metaphorically used words in discourse. Metaphor and Symbol 22, 1-39.

Richards, I. A. (1936). The philosophy of rhetoric. Oxford: Oxford University Press.

Searle, J. (1980). The background of meaning. In J. Searle, F. Kiefer \& M. Bierwisch (eds), Speech act theory and pragmatics (pp. 22-43). Dordrecht: Reidel.

Semino, E. \& Steen, G. J. (2008). Metaphor in literature. In R. W. Gibbs (ed.), The Cambridge handbook of metaphor and thought (pp. 232-246). Cambridge: Cambridge University Press.

Sitnikova, T., Holcomb, P. \& Kuperberg, G. (2008). Neurocognitive mechanisms of human comprehension. In T. F. Shipley \& J. Zacks (eds), Understanding events: how humans see, represent, and act on events (pp. 639-683). Oxford: Oxford University Press.

Soriano, C. \& Valenzuela, J. (2009). Are conceptual metaphors accessible online? A psycholinguistic exploration of the CONTROL IS UP metaphor. In J. Valenzuela, A. Rojo \& C. Soriano (eds), Trends in cognitive linguistics: theoretical and applied models (pp. 29-49). Frankfurt: Peter Lang.

Steen, G. J. (2007). Finding metaphor in grammar and usage. Amsterdam \& Philadelphia: John Benjamins.

Steen, G. J. \& Gibbs, R. (2004). Questions about metaphor in literature. European fournal of English Studies 8, 337-354.

Steen, G. J., Dorst, A. G., Herrmann, B. J., Kaal, A., Krennmayr, T. \& Pasma, T. (2010). A method for linguistic metaphor identification: from MIP to MIPVU. Amsterdam \& Philadelphia: John Benjamins.

Stockwell, P. (2006). Cognitive Poetics: an introduction. London and New York: Routledge.

Turner, M. (1996). The literary mind: the origins of thought and language. New York: Oxford University Press.

Tsur, R. (2017). Poetic conventions as cognitive fossils. New York: Oxford University Press.

Yang, X. (2015). A cognitive poetic approach to the function of metaphor. Advances in Literary Study 3, 84-88. 


\section{Appendices}

Appendix A. Poetic excerpts used in Task 1, their underlying conceptual metaphors, and related/unrelated target words.

\section{Beck 1 \\ from 'The Copper Husk Allegory' \\ The farmhouse is still / \\ against a voiceless hill \\ A HILL IS A PERSON \\ Beck 2 \\ from 'The Copper Husk Allegory' \\ One farmer is sitting in the darkened barn \\ w The motor's singing him to sleep \\ DEATH IS SLEEP}

\section{Beck 3}

from 'The Copper Husk

Allegory'

Only one farmer /

has sought the way of pain

LIFE IS A DIFFICULT

JOURNEY

\section{Peterson 1}

from 'How We Got Here'

We ate our hunger and

moaned /

as it grew heavier inside us

REPRESS I N G IS E A T IN G

\section{related}

human

child

mother

father

\section{related}

to decay

to die

to vanish

to rest

\section{related}

acceptance

confrontation journey

related

to subdue to suppress to keep

back

\section{unrelated}

cupboard

chair door

desk

unrelated

to wonder

to rely

to stay

to dig

unrelated

encounter

revolution

celebration assistance

company

\section{unrelated}

to control to suspect

to relate

to gauge

to produce 


\begin{tabular}{|c|c|c|c|c|c|c|c|c|}
\hline $\begin{array}{l}\text { Peterson } 2 \\
\text { from 'How We Got Here' } \\
\text { We ate the future/ } \\
\text { Before it limped away } \\
\text { POSSESSION IS EAT ING }\end{array}$ & $\begin{array}{l}\text { related } \\
\text { to keep }\end{array}$ & to receive & to embrace & to get & $\begin{array}{l}\text { unrelated } \\
\text { to reject }\end{array}$ & to stare & to close & to dance \\
\hline $\begin{array}{l}\text { Lim } 1 \\
\text { from 'Night Vision' } \\
\text { Years later, I lie awake / } \\
\text { In the deep enclosing heart of } \\
\text { a household } \\
\text { A L IVE IS AW A KE }\end{array}$ & $\begin{array}{l}\text { related } \\
\text { to breathe }\end{array}$ & to live & to grow & to exist & $\begin{array}{l}\text { unrelated } \\
\text { to fly }\end{array}$ & to cry & to jump & to dance \\
\hline $\begin{array}{l}\text { Lim } 2 \\
\text { from 'Night Vision' } \\
\text { Years later, I lie awake / } \\
\text { In the deep enclosing heart of } \\
\text { a household } \\
\text { AFFECTION IS } \\
\text { CONTA INMENT }\end{array}$ & $\begin{array}{l}\text { related } \\
\text { comfort }\end{array}$ & box & container & affection & $\begin{array}{l}\text { unrelated } \\
\text { water }\end{array}$ & sunrise & weather & dinner \\
\hline $\begin{array}{l}\text { Lim } 3 \\
\text { from 'Night Vision' } \\
\text { Years later than in a crib / } \\
\text { floating among the white } \\
\text { moon faces that beam and } \\
\text { grasp } \\
\text { PEOPLE ARE WHITE } \\
\text { MOON FACES }\end{array}$ & $\begin{array}{l}\text { related } \\
\text { mother }\end{array}$ & family & people & doctor & $\begin{array}{l}\text { unrelated } \\
\text { food }\end{array}$ & ball & bottle & plate \\
\hline
\end{tabular}




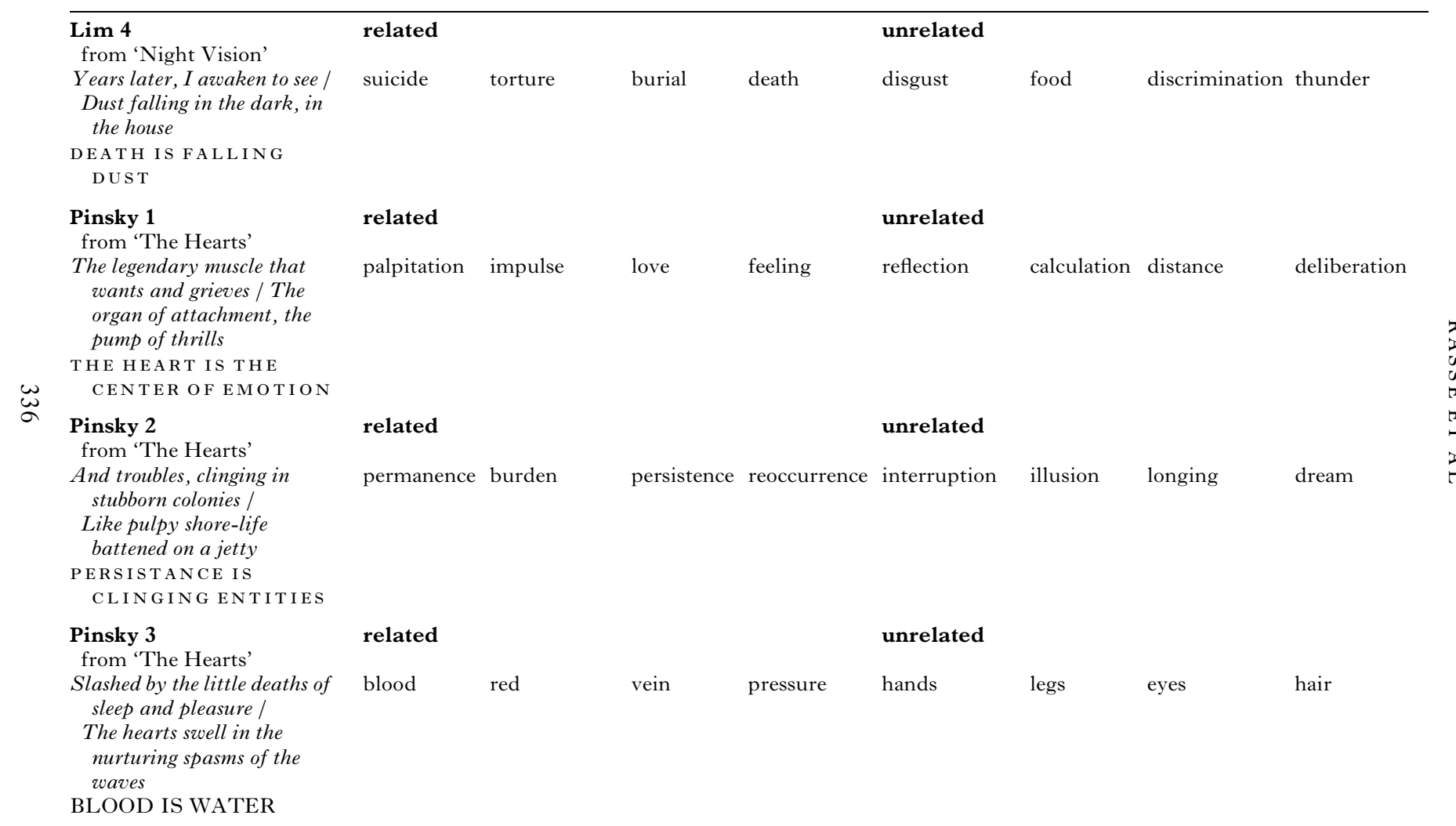




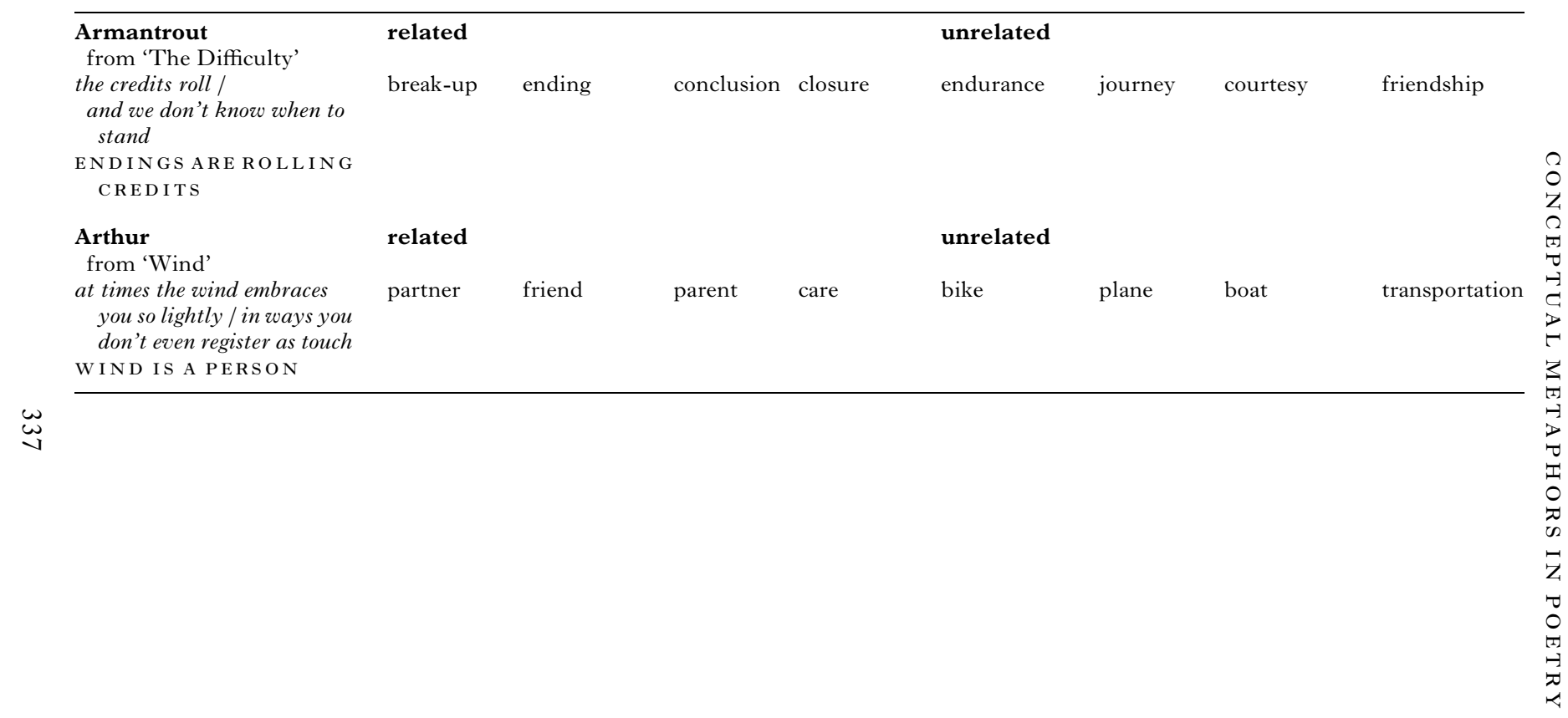




\section{Appendix B}

Instructions for Task 2 .

Please read the following instructions carefully. These will help you to complete the final part of this survey:

Metaphors describe one thing in terms of another. Usually they describe something abstract in more concrete terms.

For example, in the common English sayings "She's without direction in life" or "He's at a crossroads", life is conceptualized as a journey.

Another example is talking about ideas in terms of food, e.g., "That class gave me food for thought", or about theories in terms of buildings, e.g., "Is that the foundation of your theory?".

The mapping between an abstract concept, e.g., L IFE, and a more concrete concept, e.g., JOURNEY, is called conceptual metaphor. Some common conceptual metaphors are:

L I F E IS A J O U RNEY, e.g., I don't know where I'm headed; He just sails through life.

L OVE IS MADNESS, e.g., I'm crazy about him; She's madly in love. GOOD IS UP / BAD IS DOWN, e.g., I'm over the moon; He's feeling down.

Metaphors are not only present in everyday conversations, but also pervasive in literature. Take Emily Dickinson's poem as an example

Because I could not stop for Death -

He kindly stopped for me

The Carriage held but just Ourselves And Immortality

In this poem, death is conceptualized as departure. Dickinson talks about death as if it was a person; for example, she explains how death, like a coachman, comes to take away someone who is dying. This way, the author makes use of the metaphorical conception of DEATH IS DEPARTURE. 
Appendix C. Descriptive statistics of items significantly different among

\begin{tabular}{|c|c|c|c|c|}
\hline poem name & lexical item & word relation & mean & standard deviation \\
\hline \multirow[t]{8}{*}{ Beck 1} & human & related & 1.74 & 0.69 \\
\hline & child & related & 1.24 & 0.43 \\
\hline & mother & related & 1.34 & 0.48 \\
\hline & father & related & 1.32 & 0.53 \\
\hline & door & unrelated & 1.48 & 0.69 \\
\hline & cupboard & unrelated & 1.11 & 0.39 \\
\hline & chair & unrelated & 1.11 & 0.39 \\
\hline & desk & unrelated & 1.03 & 0.16 \\
\hline \multirow[t]{8}{*}{ Beck 2} & rest & related & 3.61 & 0.59 \\
\hline & decay & related & 1.89 & 0.86 \\
\hline & die & related & 2.39 & 1.03 \\
\hline & vanish & related & 1.74 & 0.89 \\
\hline & stay & unrelated & 2.32 & 0.87 \\
\hline & rely & unrelated & 1.42 & 0.72 \\
\hline & dig & unrelated & 1.37 & 0.71 \\
\hline & wonder & unrelated & 2.13 & 0.99 \\
\hline \multirow[t]{8}{*}{ Beck 3} & journey & related & 3.26 & 0.79 \\
\hline & acceptance & related & 2.45 & 1.03 \\
\hline & confrontation & related & 2.42 & 0.95 \\
\hline & encounter & related & 2.0 & 0.87 \\
\hline & revolution & unrelated & 1.92 & 0.97 \\
\hline & celebration & unrelated & 1.26 & 0.55 \\
\hline & assistance & unrelated & 1.13 & 0.34 \\
\hline & company & unrelated & 1.53 & 0.73 \\
\hline \multirow[t]{8}{*}{ Lim 1} & exist & related & 3.32 & 0.77 \\
\hline & live & related & 3.0 & 0.9 \\
\hline & breathe & related & 2.34 & 0.88 \\
\hline & grow & related & 2.5 & 0.9 \\
\hline & fly & unrelated & 1.11 & 0.39 \\
\hline & cry & unrelated & 1.76 & 0.75 \\
\hline & jump & unrelated & 1.24 & 0.63 \\
\hline & dance & unrelated & 1.03 & 0.16 \\
\hline \multirow[t]{8}{*}{$\operatorname{Lim} 3$} & doctor & related & 1.39 & 0.95 \\
\hline & mother & related & 2.84 & 0.95 \\
\hline & family & related & 3.16 & 0.86 \\
\hline & people & related & 3.16 & 0.86 \\
\hline & food & unrelated & 1.03 & 0.16 \\
\hline & ball & unrelated & 1.21 & 0.47 \\
\hline & bottle & unrelated & 1.39 & 0.72 \\
\hline & plate & unrelated & 1.05 & 0.23 \\
\hline \multirow[t]{7}{*}{$\operatorname{Lim} 4$} & suicide & related & 1.53 & 0.89 \\
\hline & torture & related & 1.55 & 0.60 \\
\hline & death & related & 2.34 & 0.97 \\
\hline & disgust & unrelated & 1.55 & 0.69 \\
\hline & food & unrelated & 1.08 & 0.27 \\
\hline & discrimination & unrelated & 1.32 & 0.53 \\
\hline & thunder & unrelated & 1.26 & 0.50 \\
\hline
\end{tabular}

related and unrelated words. 
RASSE ET AL

\begin{tabular}{|c|c|c|c|c|}
\hline poem name & lexical item & word relation & mean & standard deviation \\
\hline \multirow[t]{8}{*}{ Pinsky 1} & palpitation & related & 3.08 & 1.0 \\
\hline & impulse & related & 2.97 & 0.97 \\
\hline & love & related & 3.11 & 0.98 \\
\hline & feeling & related & 3.47 & 0.89 \\
\hline & reflection & unrelated & 2.21 & 0.93 \\
\hline & calculation & unrelated & 1.29 & 0.52 \\
\hline & distance & unrelated & 1.37 & 0.67 \\
\hline & deliberation & unrelated & 1.47 & 0.76 \\
\hline \multirow[t]{8}{*}{ Armantrout } & ending & related & 3.87 & 0.41 \\
\hline & conclusion & related & 3.61 & 0.86 \\
\hline & closure & related & 3.47 & 0.8 \\
\hline & break-up & related & 1.97 & 0.49 \\
\hline & endurance & unrelated & 2.08 & 1.05 \\
\hline & journey & unrelated & 2.63 & 1.10 \\
\hline & courtesy & unrelated & 1.95 & 1.01 \\
\hline & friendship & unrelated & 1.66 & 0.85 \\
\hline \multirow[t]{8}{*}{ Arthur } & partner & related & 2.42 & 1.03 \\
\hline & friend & related & 2.53 & 0.83 \\
\hline & parent & related & 2.03 & 0.97 \\
\hline & care & related & 2.79 & 0.84 \\
\hline & bike & unrelated & 1.08 & 0.27 \\
\hline & plane & unrelated & 1.05 & 0.23 \\
\hline & boat & unrelated & 1.13 & 0.34 \\
\hline & transportation & unrelated & 1.32 & 0.57 \\
\hline
\end{tabular}

\section{Appendix D}

Poetic excerpts used in Task 2.

1. 'Copper Husk Allegory'

The sky is muffling

The fields with flakes

The farmhouse is still

Against a voiceless hill

The wind rushes in

Through the open kitchen door, and snow drifts over the chairs

\section{2. 'How We Got Here'}

We ate everything in the house.

The yard picked clean -

Nothing even that any

Starving memory could hold out for.

We ate our anger

and soon our love 
and the patience of others.

We ate our hunger and moaned

as it grew heavier inside us.

3. 'Night Vision' (1)

Years later, I lie awake

In the deep enclosing heart of a household.

Years later than in a crib,

Floating among the white moon faces that beam and grasp.

4. 'Night Vision' (2)

Years later, flecking the eyes,

Faces like spheres wheeling, savoring my self.

Years later, I awaken to see

Dust falling in the dark, in the house

5. 'Metaphor'

A poem is a weather-tested craft

whose worthiness is ultimately found

by how it sails the oceanic rift

between assaulting waves that never end

6. 'The Hearts'

The legendary muscle that wants and grieves,

The organ of attachment, the pump of thrills

And troubles, clinging in stubborn colonies

7. 'The Difficulty"

The film, like many others,

Claims we'll enjoy life

Now that we've come through

Difficulties, dangers

So incredibly condensed

That they must be over

when the credits roll

and we don't know

when to stand 


\section{8. 'Wind'}

it's true sometimes I cannot

stop myself from spilling

the recycling

unpetalling apple blossoms raiding

a picnic

making off with napkins I'm nothing

until I happen

flipping an umbrella outside-in

throwing its owner

into a fumble

at times embracing you so lightly

in ways you don't even register

as touch 